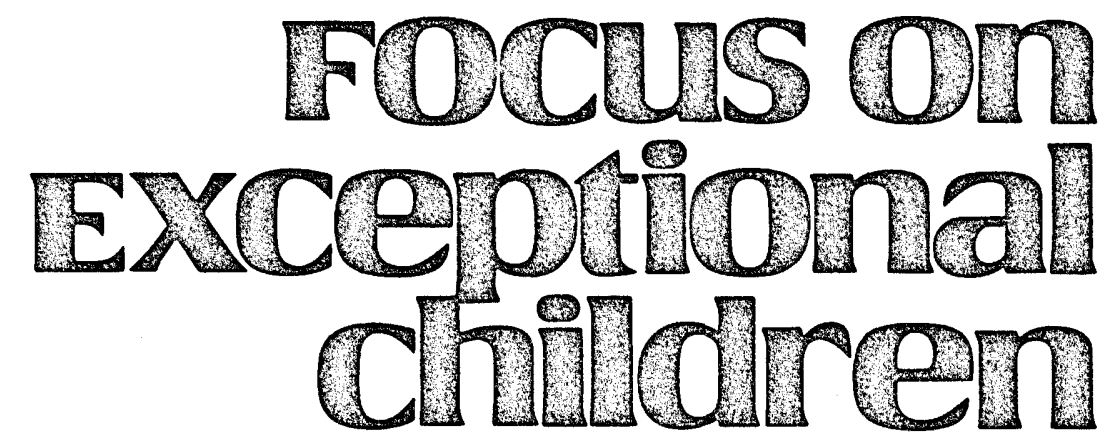

\title{
Issues in Handwriting Instruction
}

\section{Steve Graham}

My 6-year-old daughter, Leah, just finished her first year of school in a whole language classroom. Because of my personal interest in my daughter's education and my professional preoccupation with children's writing and writing instruction, I kept a log of the practices Leah's teachers used throughout the year to help her and her kindergarten classmates grow as writers. The most prominent practices included:

- providing children with frequent opportunities to compose on topics of their own choosing, primarily by dictating stories to an adult or by writing out their compositions using pictures, known words, and invented spellings.

-encouraging students to work on the same composition over a series of days.

- creating a classroom environment where children's ideas and efforts were valued and supported.

—using reading and other language skills to support the development of writing, and vice versa.

-encouraging students to share their work with classmates, other adults in the school, and parents.

I was very pleased with what I observed during the course of the year, as these practices are consistent with my own beliefs about the ingredients essential to a sound writing program (Graham, 1992; Graham \& Harris, 1988; MacArthur, Schwartz, \& Graham, 1991). I did, however, have one serious reservation concerning the writing program in my daughter's class. Very little attention was focused on helping children master handwriting.

Although my daughter was able to dictate delightful narratives concerning a real or imagined adventure, writing her ideas on paper was slow, laborious, and messy. When writing she relied almost exclusively on capital letters and had developed some unusual models for writing these letters. For example, when forming a capital $U$ she would start on the baseline, curve up to the left to form one half of the $U$, lift her pencil from the paper, return to her starting point on the baseline, and swing up to the right to complete the other half of the $U$ !

While I was not overly concerned that Leah's writing was slow, messy, and capitalized (a common state of affairs for kindergartners), I was worried about the awkward and inefficient habits she had developed for forming a considerable number of capital letters.

Steve Graham is a professor at the University of Maryland, College Park. 
If this pattern continued with lowercase manuscript letters and eventually with cursive script, her idiosyncratic style would likely hobble her ability to transcribe her own thoughts quickly or record the thoughts of others. As we shall see shortly, handwriting and other text production skills play an important role in children's development as writers.

My wife and I addressed our concern about our daughter's handwriting at home this summer. Using the ZanerBloser alphabet (Hackney \& Lucas, 1993) as a model, Leah learned how to form upper- and lowercase manuscript letters. As she practiced each letter, we gave her feedback and reinforcement for her efforts. We further encouraged her to use the handwriting skills she learned when writing a note to grandmother, a friend, and so forth. In effect, we did what many parents before us have done-taught at home the skills a child has not acquired at school (Taylor, Harris, \& Pearson, 1988).

Despite my concern about handwriting, the composition program at my daughter's school and a growing number of

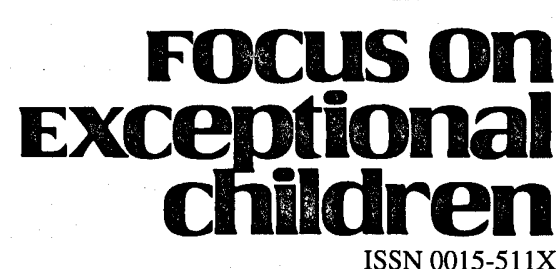

FOCUS ON EXCEPTIONAL CHILDREN (USPS 203-360) is published monthly except June, July, and August as a service to teachers, special educators, curriculum specialists, administrators, and those concerned with the special education of exceptional children. This publication is annotated and indexed by the ERIC Clearinghouse on Handicapped and Gifted Children for publication in the monthly Current Index to Journals in Education (CIJE) and the quarterly index, Exceptional Children Education Resources (ECER). It is also available in microfilm from Xerox University Microfilms, Ann Arbor, MI. Subscription rates: Individual, $\$ 27$ per year; institutions, $\$ 36$ per year. Copyright (C) 1992, Love Publishing Company. All rights reserved. Reproduction in whole or part without written permission is prohibited. Printed in the United States of America. Second class postage is paid at Denver, Colorado. POSTMASTER: Send address changes to:

Love Publishing Company

Executive and Editorial Office

1777 South Bellaire Street

Denver, Colorado 80222

Telephone (303) 757-2579

Edward L. Meyen

University of Kansas

Richard J. Whelan

University of Kansas Medical Center
Stanley F. Love

Publisher
Glenn A. Vergason Georgia State University
Holly T. Rumpler Senior Editor other schools represents a marked improvement over what has previously passed as writing instruction in this nation. In too many instances, writing programs have focused almost exclusively on mechanics and grammar, devoting little time or attention to handwriting (cf. Bridge \& Hiebert, 1985; Christenson, Thurlow, Ysseldyke, \& McVicar, 1989). As more and more schools adopt whole language programs or other practices that heavily emphasize meaning, however, it is important that basic writing tools such as handwriting not be overlooked. As Duffy (1992) has so rightly stressed, students should not "receive one-sided messages about what really counts" (p. 443). A reasonable balance between both meaning and form needs to be achieved.

This paper examines critical issues in handwriting instruction, including the need for systematic and formal instruction. The importance of handwriting is also examined, especially in terms of the role of handwriting and other text production skills in children's development as writers. While the issues addressed are pertinent to all children, concerns particularly relevant to students receiving special services are highlighted.

\section{THE IMPORTANCE OF HANDWRITING}

\section{The Role of Handwriting and Other Text Production Skills in Writing Development}

Currently, the most popular description of the composing process is a model developed by Hayes and Flower (1986). They characterize skilled writing as a goal-directed activity in which writers accomplish their goals by deftly combining the cognitive processes of planning, sentence generation, and revising. Of particular importance to the current discussion are the processes involved in sentence generation or, in other words, translating the writer's plans into written language.

The mental demands involved in translation are substantial. The writing plan consists largely of pointers to information or directions about what needs to be done (Hayes \& Flower, 1986). This includes explaining briefly sketched ideas and notes, putting nonverbal ideas into written form, and carrying out directions (e.g., "Make this part exciting."). During translation, the writer is faced with a variety of problems related to discourse coherence, structure, and production (Humes, 1983). These include the coordination of processes and knowledge involving handwriting (or typing), spelling, punctuation, capitalization, word choice, textual connections, syntax, clarity, and so forth. For writers, 
the mental load imposed by translation "becomes lighter as an increasing number of writing skills become automatic rather than consciously driven" (Bridwell, 1981, p. 96).

Berninger and her colleagues (Berninger, Yates, Cartwright, Rutberg, Remy, \& Abbot, in press; Berninger, Whitaker, \& Swanson, 1992) have argued that the text production skills involved in translation are especially important in beginning writers' development. They propose that for children in the primary grades translation involves two separate components: the text generator and the transcriber. The text generator translates the child's ideas into oral language, while the transcriber transforms the child's words into written text. While they propose that these two components generally mature simultaneously, the research by Berninger and her colleagues suggests that different skills contribute to the development of each component (Berninger et al., in press; Berninger, Cartwright, Yates, Swanson, \& Abbott, 1992). They further indicate that when the transcriber does not develop normally or in concert with the text generator, the degree to which higher level composition skills are acquired may well be affected (Berninger et al., in press).

How can difficulty in acquiring text production skills such as handwriting affect children's writing? For inexperienced or poor writers who have not yet mastered the mechanics of writing, having to attend consciously to the lower level skills of getting language onto paper may interfere with higher order writing skills such as planning or content generation. For example, the search for a specific typing key or the laborious production of individual letters may cause the writer to forget plans and ideas already developed or may disrupt the associative processes involved in content generation (Graham, 1990; MacArthur \& Graham, 1987).

Scardamalia, Bereiter, and Goelman (1982) have suggested that allocating considerable attention to the mechanical requirements of writing may interrupt or interfere with higher order writing processes in three ways. One, having to pay attention to mechanical demands may lead the writer to forget already developed intentions and meanings. Two, simultaneously allocating conscious attention to trying to produce a unit of text while trying to plan the next unit may further interfere with the planning process, resulting in writing that is less coherent and complex. Three, when writers are preoccupied with mechanical concerns, they may have less time to make their expressions precisely fit their intentions at the point of translation.

A second means by which mechanical demands such as handwriting may interfere with writing involves how fast students can write. Students' writing speed may not be fast enough to keep up with their thoughts. As a result, ideas and plans already developed may be lost and content generation may be interrupted.

Perhaps most importantly, difficulties with the mechanics of writing may affect students' persistence, motivation, and sense of efficacy (Berninger et al., in press; Graham, 1990; Graham, Schwartz, \& MacArthur, in press; Harris \& Graham, 1992; MacArthur \& Graham, 1987). Students who have considerable difficulty with handwriting, spelling, and other text production skills may avoid writing whenever possible and come to doubt their own capabilities as writers. As Daly and his colleagues (cf. Daly \& Shamo, 1978; Faigley, Daly, \& Witte, 1981) have shown, people's beliefs about their own writing capabilities are related to how frequently and how well they write.

Finally, students who are frustrated with mechanics may place too much emphasis on text production when writing (Issacson, 1989). For example, students with learning disabilities typically have difficulty with handwriting and other text production skills (Graham, Boyer-Schick, \& Tippets, 1989; Graham \& Harris, 1989). Nonetheless, when asked to describe good writing, what good writers do, how to prepare a paper for a younger child, and how to make another person's paper better, students with learning disabilities participating in a recent study (Graham et al., in press) emphasized form as much as substance. In contrast, students without learning problems were much more likely to emphasize substance over form in their descriptions.

In considering the role of handwriting and other text production skills in children's writing development, it is also important to note at what point children typically practice these skills competently enough that interference and cognitive overload during writing are not serious problems. This usually occurs by the end of elementary school (Scardamalia \& Bereiter, 1986). For students with learning problems, however, these skills appear to be acquired much more slowly. MacArthur and Graham (1987) reported that the dictated stories of fifth- and sixth-grade students with learning disabilities were better than the stories they produced either by hand or on a word processor. Graham (1990) also found that the mechanics of writing interfered with the length and quality of essays produced by fourthand sixth-grade students with learning disabilities.

\section{An Instructional Time Thief}

The consequences of failing to learn to write legibly and quickly are not limited to children's development as writ- 
ers. Enstrom (1967) aptly dubbed poor handwriting an instructional time thief. Students with handwriting difficulties often take longer to complete written assignments and may have difficulty taking notes during content lectures (Graham \& Miller, 1980). Teachers, on the other hand, lose precious time trying to read papers that are illegible. Moreover, research has shown that teachers' judgments (or grades) concerning the content of a student's paper are influenced by legibility (cf. Briggs, 1970; Markham, 1976).

\section{ISSUES IN HANDWRITING INSTRUCTION}

Four issues critical to handwriting instruction are considered next. The issues range from the need for explicit handwriting instruction to the use of self-regulation procedures as part of the handwriting program.

\section{Issue \#1: Should Handwriting Be Taught Directly Out- side the Context of Children's Actual Writing?}

Although very few countries have a national handwriting policy and most of the available literature concentrates on how to teach the Roman alphabet, a common aim in handwriting instruction can be found worldwide-"the development of an individual style that is, first and foremost, legible as well as fast, fluent, and aesthetically pleasing" (Holbrook, 1985, p. 2136). Nevertheless, considerable disagreement exists in the United States on how this aim can best be met. In some schools, handwriting is taught systematically using commercially prepared materials or teacher developed programs. Other schools have no formal program (Addy \& Wylie, 1973); handwriting is taught sporadically, with advice and practice given only on an individual, as needed basis.

The whole language movement has intensified the debate on how handwriting can best be mastered. Teachers ascribing to a whole language philosophy commonly believe that writing conventions, such as letter formation, are best learned by using them naturally and in concert with each other (Watson, 1989). From a whole language perspective, "a skill should be taught when a particular child needs it for something else the child is working on" (Edelsky, 1990, p. 9). For example, when a child is writing the teacher may give a hint to help the child form a letter correctly.

In contrast, most traditional approaches to handwriting instruction provide separate and explicit instruction in how to form each individual letter. Additionally, letters are often presented in a specific order so that similarities or differ- ences in letter formation can be emphasized (Graham \& Miller, 1980). The main difference between traditional and whole language practices, however, does not lie in setting up a prescribed sequence for teaching handwriting skills. As Edelsky (1990) aptly suggests, "a skills viewpoint does not require a belief in a skills hierarchy" (p. 9). Teachers using a traditional approach can order or reorder the skills they teach based on the needs of their students. The main difference between these two practices involves decontextualizing handwriting instruction. With the traditional approach, students are introduced to and practice letter formation outside of the context of writing.

Surprisingly, the question posed here (Should handwriting be taught directly outside the context of children's actual writing?) has not been directly addressed by the educational research community. While it is noteworthy that many schools in the United Kingdom have reintroduced systematic teaching of handwriting after a period of laissezfaire instruction (Bailey, 1988), empirical investigations comparing the handwriting development of children receiving traditional, incidental, or whole language instruction have not been conducted. Nevertheless, I would like to offer several observations pertinent to this issue.

An important part of teaching handwriting is capitalizing on "teachable moments." For example, in Writers' Workshop, a process approach to writing compatible with whole language practices, students spend the majority of their time writing (Atwell, 1987; Calkins, 1986; MacArthur et al., 1991). As students work on their writing projects, the teacher circulates around the room observing and conferencing with them. During this time, the teacher may elect to do some "on-the-spot teaching," either at the request of a student ("How do you make a capital $K$ ?"), as a consequence of an observation (a left-handed student whose writing paper is positioned as if he were right-handed), or as a result of an insight obtained during a teacher-student conference (a student's writing is difficult to read or share because there are no spaces between words). During the course of the day or several days, the teacher may also notice that several children are exhibiting a similar problem and may decide to bring them together for a "mini-lesson" to address their common difficulty.

While capitalizing on such "teachable moments" as children write should be an integral part of a writing program, I would submit that for many children, especially students with learning problems, this instruction will not be enough. One reason is that handwriting will not necessarily be uppermost in many teachers' minds when they observe students 
working or conference with them individually. For teachers using whole language practices or process approaches to writing, meaning is seen as more important than form and, thus, the writer's content and ideas receive greater emphasis than handwriting and other text production skills (Graham, Harris, MacArthur, \& Schwartz, 1991a; Watson, 1989).

During conferences in Writers' Workshop, for instance, teachers often have multiple goals (MacArthur et al., 1991). They listen responsively as students read and tell about their writing, encourage students to think about and articulate their goals and problems, help them extend their thinking, and coach them in applying the skills and strategies they are learning to master. Consequently, because handwriting is sharing the bill with so many competing concerns and meaning is emphasized over form, teachers using Writers' Workshop or similar approaches are not likely to devote a large proportion of their "teachable moments" or mini-lessons to handwriting. In contrast, teachers who emphasize text production skills while children are writing may run the risk of giving children the wrong message. Students may come to believe that form, not communication, is the primary purpose for writing.

Another reason that capitalizing on "teachable moments" is not an adequate substitute for explicit and direct handwriting instruction for many children is that this practice is basically reactive rather than proactive. As teachers conduct "on-the-spot teaching" or institute mini-lessons based on their observations and conferences with students, they are often responding to either established problems or developing difficulties. Once a problem has become well established, it may take an extended effort on the part of the teacher and the student to develop a more desirable practice (Graham, 1992).

For developing difficulties, it is important that teachers identify and address them quickly before they become an established problem. For example, if some of the students in a second-grade class are making the transition to cursive script and experimenting with forming particular cursive letters in their writing, the teacher needs to spot awkward and ineffective approaches to letter formation before they become habitualized. This places a considerable demand on the teacher. While providing explicit and direct handwriting instruction to help students learn cursive script will not eliminate the need for "on-the-spot teaching," it should reduce the number of established and developing difficulties that the teacher has to address.

Learning to type provides and excellent analogy to illustrate the importance of explicit instruction in handwriting.
In watching children with learning disabilities learn to use a word processor for writing, my colleagues and I have observed that children who do not receive keyboarding instruction are often frustrated and their writing hampered by their slow typing speed (MacArthur et al., 1991). Similarly, we have found that typing accuracy and fluency are related to the length and quality of their written products (MacArthur \& Graham, 1987).

Personally, the need for typing instruction became evident to me when I taught myself to type as I learned to use a word processor. Unfortunately, I developed some bad habits, such as using three to six fingers and having to look at the keyboard, that clearly inhibited my development. Discovery is not an especially effective approach for learning either typing or handwriting. I will probably always envy those whose fingers fly over the keyboard.

\section{Summary}

What I propose in this paper is that teachers need to provide handwriting instruction both outside and during children's actual writing. First, teachers should take a proactive stand and explicitly and directly help students establish the habits and patterns that facilitate the development of legible and fluent writing. This includes teaching students an efficient pattern for forming individual letters, including modeling the formation of each letter, providing practice, encouraging self-evaluation, and giving feedback. Teachers also need to make sure that students develop a reasonable grip for holding a pen or pencil as well as learn how to properly position the paper they are writing on. Major handwriting programs such as the one produced by Zaner-Bloser (Hackney \& Lucas, 1993) provide an excellent resource for developing these skills. As my daughter indicated to me, it is easier to write when you "know the way of it."

It is important to keep in mind that handwriting is a motor skill and that regular practice in forming individual letters is essential in the early stages of development (Bailey, 1988). This does not imply that students should spend hours copying rows of letters. Quality of practice is more important than quantity. Once a letter is introduced, students should spend a short time carefully practicing how to form the letter, receive help as needed, and evaluate their own efforts. Individual letters should also be reviewed periodically to reinforce the method for forming the letter and to provide additional practice and correction as necessary.

The bulk of children's practice in handwriting, however, should take place within the context of writing. Good handwriting instruction depends on a composition program that 
stimulates children to write frequently. The more children write, the more their handwriting skills become automatic or habitual, resulting in a gradual increase in speed (Graham \& Miller, 1980).

As children write, handwriting instruction should focus on addressing individual student's difficulties and reinforcing the handwriting skills that the teacher has explicitly introduced. For instance, a teacher may notice that a student is having difficulty forming a letter while writing. During a short mini-lesson or during a teacher-student conference, the teacher could review how the letter is formed. As another example, the teacher could quietly and privately reinforce students for using a pen or pencil grip presented earlier during the year.

\section{Issue \#2: Are Slanted Manuscript Alphabets Superior to the Traditional Manuscript Alphabet?}

Both manuscript and cursive writing are emphasized inmost elementary schools (cf. Addy \& Wylie, 1973; Koenke, 1986). Manuscript is commonly taught in kindergarten through grade 2, whereas cursive writing usually begins in grades 2 or 3 . The practice of introducing manuscript first and then switching to cursive writing has not been without controversy, though. Some educators have challenged the desirability of the switch, leading to the recommendation that only manuscript be taught (Groff, 1964; Templin, 1963) or the more controversial advice that cursive be emphasized from the start (cf. Early, 1973). The merits of this last suggestion are questionable, however, because manuscript writing is more legible than cursive writing, leads to greater gains in reading achievement, can be written as fast, and is easier to learn (Askov \& Peck, 1982; Graham \& Miller, 1980).

Currently, the most prominent spin on the manuscript/ cursive controversy in the United States focuses on the formation and slant of the manuscript alphabet. Several educators, most notably Donald Thurber (1983), have modified the traditional manuscript alphabet (characterized by round, upright letters that resemble type) so that all of the letters are slanted and most of the lowercase manuscript letters resemble their cursive counterparts. The purpose of these modifications was to make the transition between manuscript and cursive writing easier and more efficient. Thus, the former issue of learning one style versus two styles has given way to a new controversy involving the power of different models of manuscript to promote the learning of a second style of penmanship, namely cursive writing.
Although the issues concerning the efficacy of traditional manuscript versus the newer, slanted manuscript styles are simple and straightforward, the debate has become unnecessarily muddled because some of the participants have failed to distinguish between claims for different alphabets and claims for the methods used to teach them (cf. Ourada, 1993; Thurber, 1993a). While instructional procedures are important, they do not provide support for using a particular style of script.

The debate has also generated a number of inaccurate, unsubstantiated, and frivolous claims. For instance, Thurber (1983) indicated that traditional manuscript writing had "resulted in school's producing a nation of rather poor writers" (p. 3) and that this method of writing may hinder beginning reading development. However, no evidence has shown that the traditional manuscript alphabet has a detrimental effect on children's writing. Furthermore, the use of traditional manuscript in the early grades may actually facilitate reading development. In studies where young children learned either manuscript or cursive writing, the teaching of manuscript led to greater gains in reading achievement (Cutright, 1936; Houston, 1938; Long \& Mayer, 1931; Voorhis, 1931).

\section{The Programs Evaluated}

Traditional manuscript is presently used in the ZanerBloser handwriting program (Hackney. \& Lucas, 1993), whereas slanted manuscript letters are used in the programs published by Scott, Foresman (Thurber, 1993b) and McDougal, Littell (1993). I examined each program, the arguments of various advocates, and the available research literature to identify the most salient claims for replacing traditional manuscript with a slanted manuscript alphabet. The claims fell into two basic categories: one, slanted manuscript makes the transition to cursive writing easier and, two, it is superior because letters are formed using a single, continuous stroke.

Evaluating these claims was complicated by two factors. First, there has been little scientific interest in them. Second, methodological problems were evident in all of the studies reviewed. Almost uniformly, researchers have failed to control for differences in teaching methodology when evaluating the two styles of manuscript writing. In the typical experiment, one group of students was taught traditional manuscript using the Zaner-Bloser program, while another group of students was taught slanted manuscript with the Scott, Foresman program. Any conclusions regarding the effects of manuscript style in these 
studies must therefore be tempered because of the confounding influence of teaching methodology. In addition, neither students nor instructors were randomly assigned in most studies, allowing for the generation of several competing explanations for any obtained differences between groups. Finally, many of the researchers failed to establish the reliability of their handwriting measures, jeopardizing the validity of their assessments (Graham, 1986a, 1986b).

\section{The Claims}

1. The new slanted manuscript alphabets make the transition to cursive writing easier and save considerable instructional time. A basic claim made by supporters of the Scott, Foresman (subsequently referred to by its common name, D'Nealian) and McDougal, Littell handwriting programs is that their slanted manuscript alphabets do a better job than traditional manuscript of facilitating the transition to cursive writing. They argue that because their manuscript letters are slanted and closely resemble cursive letters, the transition to cursive writing is a simple transformation, mainly involving the addition of connecting strokes (McDougal, Littell, 1993; Thurber, 1993a). They further claim that traditional manuscript makes the transition to cursive writing more difficult because students have to learn four different forms for each letter: two for manuscript (upperand lowercase) and two for cursive (Thurber, 1993a).

An analysis of the D'Nealian and McDougal, Littell alphabets, however, revealed that almost half $(46 \%)$ of the cursive letters in each program are substantially different from their manuscript counterparts. An additional $26 \%$ of the cursive letters in the McDougal, Littell program and $21 \%$ of those in D'Nealian involve small changes in letter formation, such as shortening a line or tightening a curve as a result of adding a connecting stroke to a manuscript letter. Although lowercase letters are more constant than uppercase letters, approximately $70 \%$ of all manuscript letters in both of these programs require some modification for cursive writing other than simply adding connecting strokes. Consequently, students have to learn not only all of the upper- and lowercase manuscript letters, but a modified or completely different form for most of the cursive letters. The transition to cursive writing in these programs, therefore, involves much more than a simple transformation of adding connecting strokes to manuscript letters.

Thurber $(1983,1993 \mathrm{~b})$ has further claimed that slanted manuscript alphabets cut the transition time to cursive in half. The basis for this claim, though, is unclear. Both the D'Nealian and the McDougal, Littell programs introduce cursive writing about one third of the way through second grade. By the end of the year, both programs cover all of the upper- and lowercase cursive letters. In presenting the more traditional alphabet, the Zaner-Bloser program provides two options for making the transition to cursive writing. One of the options mirrors the approach taken by D'Nealian and McDougal, Littell: students make the transition to cursive script early in second grade and cover all of the upper- and lowercase cursive letters by the end of the year. With this option, there is no difference in transition time between the two types of manuscript alphabets. With the second option, cursive writing is introduced early in third grade. Although students spend an extra year working on manuscript, the amount of time spent learning cursive is again approximately one year. As teachers demonstrated over 60 years ago, students who begin handwriting instruction with traditional manuscript can learn cursive writing in as little as 6 months (Crider, 1932; Gates \& Brown, 1929).

The claim that slanted manuscript alphabets do a better job of facilitating the transition to cursive writing is also not supported by research. In a study by Trap-Porter, Cooper, Hill, Swisher, and LaNunziata (1984), 134 firstgrade students who had been taught traditional manuscript using Zaner-Bloser and 112 first-grade students who had been taught slanted manuscript using D'Nealian copied the lowercase cursive letters from their respective programs. There were no differences between the two groups of students in the number of cursive letters omitted when copying or, more importantly, in the number of cursive strokes made correctly. Consequently, the production of cursive letters was not enhanced by instruction using the D'Nealian materials.

Farris (1982) compared the cursive writing performance of second graders who had used either the D'Nealian or Zaner-Bloser materials since kindergarten. Fifteen separate criteria were used to score each writing sample (no information on the reliability of the scores was provided). Overall, the students who had been taught traditional manuscript outperformed students in the D'Nealian group. Students in the D'Nealian group produced more misshapen letters, were more likely to extend strokes above and below the guidelines, and had greater difficulty maintaining consistency in letter size. Again, the production of cursive letters was not enhanced by the use of the D'Nealian materials.

Finally, Ourada (1993) divided 45 third-grade children into two groups on the basis of academic skills and behavior. None of the students had previously been introduced to cursive writing. One of the groups spent four weeks review- 
ing the traditional manuscript alphabet using Zaner-Bloser materials, followed by eight weeks of cursive writing instruction using the same program. The other group followed the same schedule, but learned how to write manuscript and cursive script using the D'Nealian materials and alphabet. A writing sample taken at the end of the 12-week instructional period was scored for overall legibility as well as letter formation, slant, and size (no information on the reliability of the scores was provided). Since the obtained scores were not analyzed statistically, I conducted a series of chi-square analyses using the data presented in Ourada's paper. I found that the papers produced by the two groups of students did not differ in terms of letter slant $\left(\chi^{2}=.94\right)$ or letter size $\left(\chi^{2}=.38, d f=1\right)$. Furthermore, while students in the D'Nealian group were more likely to produce papers with acceptable letter formation $\left(\chi^{2}=4.2, d f=1, p<.05\right)$, this proved to be a minor distinction since there was no difference in the overall legibility of the papers written by the two groups $\left(\chi^{2}=.91, d f=1\right)$.

In summary, analyses of the available evidence failed to substantiate the claim that the transition to cursive writing is enhanced by using slanted manuscript letters. Programs using either slanted or more traditional manuscript letters allocate the same amount of time to teaching the cursive alphabet and produce either no difference or minor and unreliable distinctions in the quality of children's cursive writing.

\section{The new, slanted manuscript alphabets use continu-} ous strokes to form manuscript letters, resulting in better rhythm, greater speed, more writing, and fewer letter reversals than traditional manuscript. The claims for continuous stroke letter formation are not new. Educators who have advocated the use of cursive writing for developmental and remedial programs have long argued that cursive writing is more rhythmical, faster, and less directionally confusing than traditional manuscript (cf. Early, 1973; Fernald, 1943; McGinnis, Kleffner, \& Goldstein, 1963). Nor are these claims limited to only one style of manuscript letters. The continuous stroke method has also been used to form traditional manuscript letters.

The Zaner-Bloser program, for example, provides two options for forming manuscript letters. One option involves forming letters using four basic strokes (horizontal lines, vertical lines, slant lines, and circles and parts of circles). With this option, students lift their pencil from the paper when forming three of every five manuscript letters (e.g., $T$, $t$ ). The alternate option involves using a continuous stroke to form manuscript letters. With this option, students lift their pencil from the paper when forming less than half (44\%) of the manuscript alphabet. In comparison, students lift their pencil when forming $39 \%$ of the manuscript letters in the McDougal, Littell alphabet and $33 \%$ of the manuscript letters in the D'Nealian alphabet.

These differences are even smaller when only lowercase letters are considered. With the D'Nealian and McDougal, Littell programs, only the lowercase letters of $f, i, j, t$, and $x$ require a pencil lift. The only other letters that require a pencil lift with the Zaner-Bloser's continuous stroke option are $k$ and $y$. Neither of these two letters is especially common in English words (Zettersten, 1969).

Regardless of the similarities or differences between various approaches to forming manuscript letters, any claims regarding the advantages of a continuous stroke manuscript alphabet must be considered premature at this point. Beyond testimonials collected by publishers, no evidence has shown conclusively that students write more rhythmically, write faster, or write more as a result of learning a manuscript alphabet based on continuous stroke letter formation. These issues have simply not been addressed by handwriting researchers.

Two investigations, however, have compared the quality of handwriting produced by students taught either the D'Nealian manuscript alphabet or the Zaner-Bloser manuscript alphabet without the continuous stroke option. One of the studies was a Master's thesis (Oglesby, 1982) cited by Thurber (1993a). In this investigation, 12 underachieving second graders were randomly divided into two groups that received nine weeks of manuscript instruction using either the D'Nealian or Zaner-Bloser materials. At three-week intervals, the quality of students' writing (e.g., legibility, letter formation, spacing, and so forth) was assessed by four teachers. As in many of the other studies, no information on reliability of scores was provided. While the overall results of the study favored the D'Nealian alphabet, students' scores on specific measures were so erratic across the three testing intervals (unexplainably increasing and decreasing or visa versa) that reliability of the teachers' evaluations must be questioned, casting doubt on any interpretation of the findings from this investigation.

In the second study, Farris (1982) examined the manuscript handwriting performance of first-grade students who had used either the D'Nealian or Zaner-Bloser materials since kindergarten. Fifteen separate criteria were used to score each writing sample (no information on the reliability of the scores was provided). The results showed no significant differences between the two groups of stu- 
dents on any of the 15 criteria, including the number of letters reversed.

One reason that Farris (1982) may have failed to find any advantage for the D'Nealian manuscript alphabet is that its letters may require a greater degree of fine-motor control than the letters in the Zaner-Bloser alphabet without the continuous stroke option. This question was addressed by Duvall (1985) who used a variety of criteria to assess the difficulty of the lowercase manuscript letters in these two programs. She found that the writing hand has to change direction more often when writing the D'Nealian alphabet, do more retracing of lines, and make more strokes that occur later in children's development. However, a writer using the Zaner-Bloser alphabet has to pay more attention to visual information such as where strokes begin and meet.

Finally, several educators have argued that continuous stroke letters are especially helpful for students with special needs, reducing frustration and increasing writing fluency (Coon \& Palmer, 1993; Jordan, no date; Thurber, 1993a). Once again, though, scientific evidence does not support this position. As Brown (1993) noted, "No research has been found that would support the use of one system of handwriting over the other in remedial and special education" (p. 68).

\section{Summary}

Despite claims to the contrary by publishers and their authors, there is no credible evidence that the new, slanted manuscript alphabets make a difference for students in general or for special needs students in particular. The transition to cursive writing does not appear to be enhanced by using a special alphabet like D'Nealian. Nor have the claims concerning the advantages of continuos stroke manuscript letters been substantiated.

In fact, there are several compelling reasons why a special alphabet may not be the best choice for young children. One, young children often come to kindergarten and first grade already knowing how to write many letters. Before starting school, many children learn how to write traditional manuscript letters from their parents or preschool teachers. Learning a special alphabet such as D'Nealian during kindergarten or first grade means that these children will have to relearn many of the letters they can already write.

Adoption of a special alphabet also creates additional problems for teachers. They need to learn how to write the new script so that they can model how individual letters are formed. They further have to respond to questions from parents who are worried because the new script doesn't look like their manuscript writing (the script is unusual enough that even the publishers use traditional manuscript in student workbooks). Given the lack of evidence to support the use of slanted manuscript letters, it hardly seems worth the effort.

\section{Issue \#3: Should Children Use a Beginner's Pencil and Wide-Lined Paper?}

In many kindergarten and primary grade classrooms throughout the country, students use a "primary pencil" or "beginner's pencil" when writing (Coles \& Goodman, 1980; Lamme \& Ayris, 1983). In contrast to regular size pencils, the lead in a beginner's pencil is larger and the diameter is of medium size. Educators who have championed the use of beginner's pencils argue that the larger diameter encourages correct finger position, discourages finger movement, reduces cramping, and is easier for young children to control (Carlson \& Cunningham, 1990).

Despite the popularity of beginner's pencils, no empirical evidence supports using them instead of regular size pencils. A beginner's pencil does not appear to influence children's finger position, finger movement, or pencil control (Carlson \& Cunningham, 1990). The legibility of children's writing is also not enhanced by using a larger diameter (Carlson \& Cunningham, 1990; Lamme \& Ayris, 1983; Parker, 1972; Wiles, 1943). It is important to keep in mind, however, that these empirical observations apply to young children as a group and not any one child in particular. Carlson and Cunningham (1990) found, for example, that some of the preschool children in their study did better with a beginner's pencil and others with a regular size pencil.

Another common practice in handwriting instruction involves the use of wide-lined paper. In the D'Nealian handwriting program (Thurber, 1993b), for instance, children use three-quarter-inch ruled paper in kindergarten and onehalf-inch ruled paper in first grade. Similarly, the practice lines in the Zaner-Bloser program (Hackney \& Lucas, 1993) are approximately one-inch wide in kindergarten and five-eighths-inch wide in first grade.

Educators who have championed the use of wide-lined paper argue that it helps young children compensate for their normally farsighted vision and lack of finger strength by decreasing strain on eyesight and allowing greater freedom of movement (Waggoner, LaNunziata, Hill, \& Cooper, 1981). While researchers have not examined the effects of wide-lined paper on eye strain, a series of studies conducted at Ohio State University demonstrated that wider lines can enhance students' fine-motor control when writ- 
ing letters. In these studies, kindergarten through thirdgrade children produced more correct letter strokes when using paper with wider lines (Hill, Gladden, Porter, \& Cooper, 1982; Leung, Treblas, Hill, \& Cooper, 1979; TrapPorter, Gladden, Hill, \& Cooper, 1983; Waggoner et al., 1981). A monolithic endorsement for wide-lined paper cannot be made, however, since several groups of children participating in these investigations obtained no benefits from wider lines (Hill et al, 1982; Waggoner et al., 1981) and at least one other study (Halpin \& Halpin, 1976) found that kindergarten children gained no advantage from using specially lined paper.

\section{Summary}

In considering the place of beginner's pencils and widelined paper in children's writing programs, I would like to echo a recommendation made by Coles and Goodman (1980). They proposed that several different types of paper and writing instruments be available for children to use during school. Requiring students to use only one kind of pencil or a certain size of paper may be unnecessarily restrictive, since many children already use a variety of writing instruments and material when composing at home. The only divergence from this recommendation I would like to offer concerns the use of wide-lined paper during handwriting instruction. As the research from Ohio State University illustrates, wide-lined paper may be especially useful when young children initially practice a newly introduced letter form.

\section{Issue \#4: Should Teachers Use Self-Regulation Proce- dures as Part of the Handwriting Program?}

An important goal of academic instruction is to help students become self-regulated learners (Graham, Harris, \& Reid, 1992; Harris \& Graham, 1992)—students who take responsibility for and actively participate in their own learning. In the area of handwriting, self-regulation has typically been included as part of the instructional program in two ways: one, students are encouraged to verbalize overtly the steps in forming a letter as they are learning how to write it (self-instructions) and, two, they are asked to evaluate their success in forming letters correctly (self-evaluation).

\section{Self-Instructions}

The recommendation that students use self-verbalizations to guide letter formation originated, in large part, from a series of influential articles written by Beatrice Furner (1969a, 1969b, 1970). In one of her papers (Furner, 1970), she described a longitudinal study in which traditional handwriting programs emphasizing copying were compared to an experimental program based on principles of perceptual-motor learning. Students in the experimental program were shown how to form each letter several times, verbalized how to form letters during practice, and evaluated their success in making these letters. In addition, letters that shared common formational characteristics were taught together as a group, and teachers emphasized similarities and differences in their formation.

During the course of the three-year experiment, the quality, speed, and number of letter formation errors in students' handwriting were evaluated six times (twice each year). For both quality and speed, there were small, but significant, differences favoring students assigned to the experimental group. On the letter formation measure, the differences were much larger and, again, favored students in the experimental condition. On the basis of these findings, Furner recommended (among other things) that teachers should require students to make a mental response as well as a motor response when learning to form a letter. The mental response could include "asking children to verbalize the formational process in their own words, having children think the movement of a letter, or visualize or write a letter as it is described by another child" (Furner, 1970, p 68).

Although the findings from Furner's (1970) study were provocative, they did not validate the use of self-instructions. It was not clear what aspects of the instructional program were responsible for the observed differences between students in the experimental and control conditions.

In contrast, Robin, Armel, and O'Leary (1975) directly assessed the unique effects of self-instructions on letter formation. They evaluated the impact of three instructional conditions (i.e., self-instruction plus direct instruction, direct instruction, and no treatment) on the letter formation skills of kindergarten children. Children in the no-treatment condition took pre- and posttests only. Students in the direct instruction group copied training letters and received feedback and social reinforcement regarding their performance. Students in the self-instructions plus direct instruction group also received feedback and social reinforcement. However, when they copied letters, they simultaneously verbalized how to form them.

Even though students in the self-instructed group copied more letters correctly than students in both the direct instruction and no-treatment conditions, there were several reasons why this may be a questionable procedure to use 
with kindergarten children. First, the results showed a negative, nonsignificant correlation between handwriting performance and the number of self-instructions made by students in the self-instructed group. Second, the experimenters reported considerable difficulty in shaping and maintaining children's self-verbalizations. Third, the experimenters further indicated that the self-instructional procedures were too cumbersome to use in a regular classroom.

Graham (1983) also sought to enhance handwriting performance by combining self-instructions with more traditional practice activities. Third- and fourth-grade students with learning disabilities practiced tracing, copying, and writing two letters while simultaneously verbalizing how to form them. Students were further encouraged to evaluate and reinforce their efforts. After almost five hours of instruction, though, students made only modest gains on the two letters targeted for instruction. As in the Robin et al. (1975) study, shaping and maintaining students' self-verbalizations required a great deal of effort.

The studies by Robin et al. (1975) and Graham (1983) provide, at best, weak support for Furner's (1970) recommendation that students should verbalize how to form a letter when learning to write it. If students are encouraged to use self-verbalizations to guide letter formation, it is important they realize this is only a temporary support, to be dropped when it is no longer needed. Continued use of selfverbalizations to form letters places an unwanted constraint on how fast they can be produced (Graham, Harris, MacArthur, \& Schwartz, 1991b).

\section{Self-Evaluation}

Current handwriting programs place considerable emphasis on self-evaluation. In the materials published by McDougal, Littell (1993), for instance, students circle their best written letter or word following practice. Similarly, in the Zaner-Bloser program (Hackney \& Lucas, 1993), students evaluate their performance by responding to questions like the following: Is my letter smooth and even? Do I have two $V$ s (for $W$ ) of the same width in my letter? Does my $C$ rest on the baseline?

When used alone, self-evaluation procedures like selfmonitoring and self-evaluation are not always effective; they are much more potent when used in combination with other instructional procedures (Hallahan, Kneedler, \& Lloyd, 1983; O'Leary \& Dubey, 1979). This may explain why researchers have not concentrated on trying to determine if self-evaluation makes a unique contribution to students' growth in handwriting.
Furthermore, most of the current research has focused on students' use of transparent overlays to evaluate their handwriting performance. Transparent overlays typically contain an outline, usually 1 to $3 \mathrm{~mm}$ in width, of the target letter. The overlay is placed over the letter to determine if any of the letter strokes appear outside of the outline. A slightly different version of this procedure involves writing the target letter on a semitransparent worksheet and evaluating it by placing a template of the letter under the worksheet (Stowitschek, 1978).

The evidence accumulated so far demonstrates that children in first and second grade can reliably use transparent overlays to evaluate letter formation (Gladden, 1987; Johns, Trap, \& Cooper, 1977). Nevertheless, the educational utility of this evaluative instrument for the general school population is not clear. While Johns (1976) found that the use of transparent overlays (in combination with reinforcement or public posting of performance) improved first graders handwriting performance, Burkhalter and Wright (1984) reported that transparent overlays were no more effective than traditional self-evaluation procedures, such as circling best letters.

For students with special needs, self-evaluation procedures may be especially useful. Researchers have shown that the handwriting performance of these students can be improved when self-evaluation techniques, such as transparent overlays or circling correctly formed letters and words, are used in combination with other instructional procedures (Anderson-Inman, Paine, \& Deutchman, 1984; Blandford \& Lloyd, 1987; Fauke, Burnett, Powers, \& Sulzer-Azeroff, 1973; Kosiewicz, Hallahan, \& Lloyd, 1981; Kosiewicz, Hallahan, Lloyd, \& Graves, 1982; Stowitschek, 1978; Stowitschek, Ghezzi, \& Safely, 1987). Similarly, the number of letters practiced and on-task behavior of inattentive students can be improved by cuing them to monitor their attentional behavior (Hallahan, Lloyd, Kosiewicz, Kauffman, \& Graves, 1979; McLaughlin, 1983).

At the present time, most of the handwriting research on self-evaluation has been limited to copying letters, words, or paragraphs. Several recent studies (Anderson-Inman et al., 1984; Blandford \& Lloyd, 1987), though, have focused on more authentic tasks such as journal writing. This promising trend needs to continue to determine if selfevaluation can have a positive impact on the neatness, slant, line quality, and so forth of children's regular writing. In addition, the value of other self-regulation procedures, such as goal setting and self-reinforcement, needs to be explored. 


\section{CONCLUDING COMMENTS}

Almost 15 years ago, I remember reading with great interest an opinion in the popular press that handwriting's demise was right around the corner. This prediction was based on the premise that handwriting would become obsolete as computers and word processing became more widely available. Along the way, however, there was a surprising turn in the road. The technology that would "one day" replace handwriting was instead placed in its servicehandwriting instruction became computerized!

While computerized handwriting instruction is new and relatively untested, there are several reasons to be optimistic about its application. First, a computer can provide systematic and individualized instruction, while minimizing the demands typically placed on the teacher. With a computer, the formation of a letter can be precisely modeled, prompts or guidelines for writing the letter can be gradually faded, corrective feedback and reinforcement can be delivered when needed, and progress can be accurately monitored (Brewer, Cunningham, \& White, 1989-1990). Second, field tests of computerized handwriting programs have been positive. The computer has been used as a guide to improve the letter formation of students with and without mental retardation (Brewer et al., 1989-1990; Lally, 1982; White, Cunningham, \& Brewer, 1989). Until computers and other technological advances become more common in children's homes and the classroom, though, computerized instruction will not play a significant role in handwriting development.

Finally, all of the major handwriting programs produce instructional materials that extend to grade 6 or beyond. Unfortunately, for the upper elementary grades, these programs do not do a good job of capitalizing on what we already know about children's handwriting development. Examination of children's and adult's writing reveals that a relatively small number of errors account for a large percentage of the illegibilities in writing (cf. Horton, 1969; Lewis, 1964). For instance, four letters- $a, e, r$, and $t-$ account for almost $50 \%$ of all malformed cursive letters at any grade level. Instead of concentrating on frequent problems in the upper elementary grades, current handwriting programs repeatedly review the whole alphabet, again and again. It would be more efficient and more effective to focus instruction where it is most needed.

\section{REFERENCES}

Addy, P., \& Wylie, R. (1973). The "right" way to write. Childhood Education, 49, 253-254.

Anderson-Inman, L., Paine, S., \& Deutchman, L. (1984). Neatness counts: Effects of direct instruction and self-monitoring on the transfer of neat-paper skills to nontraining settings. Analysis and Intervention in Developmental Disabilities, 4, 137-155.

Askov, E., \& Peck, M. (1982). In H. Mitzel (Ed.), Encyclopedia of educational research (pp. 764-769). New York: The Free Press.

Atwell, N. (1987). In the middle: Reading, writing, and learning from adolescents. Portsmouth, NH: Heinemann.

Bailey, C. (1988). Handwriting: Ergonomics, assessment, and instruction. British Journal of Special Education, 15, 65-71.

Berninger, V., Cartwright, A., Yates, C., Swanson, L., \& Abbott, R. (1992). Developmental skills related to writing and reading in the intermediate grades. Manuscript submitted for publication.

Berninger, V., Whitaker, D., \& Swanson, L. (1992, February). Developmental and individual differences in planning, translating, and revising. Paper presented at the International Association of Cognitive Education, Riverside, California.

Berninger, V., Yates, C., Cartwright, A., Rutberg, J., Remy, E., \& Abbott, R. (In press). Lower-level developmental skills in beginning writing. Reading and Writing: An Interdisciplinary Journal.

Blandford, B., \& Lloyd, J. (1987). Effects of a self-instructional procedure on handwriting. Journal of Learning Disabilities, 20, 342-346.

Brewer, N., Cunningham, S., \& White, J. (1989-1990). A computerized procedure for teaching letter formation skills to mentally retarded individuals. Journal of Educational Technology Systems, 18, 185-190.

Bridge, C., \& Hiebert, E. (1985). A comparison of classroom writing practices, teachers' perceptions of their writing instruction, and textbook recommendations on writing practices. Elementary School Journal, $86,155-172$.

Bridwell, L. (1981). Rethinking composing. English Journal, 70, 96-99.

Briggs, D. (1970). Influence of handwriting on assessment. Educational Research, 13, 50-55.

Brown, V. (1993). D'Nealian handwriting: What it is and how to teach it. In G. Coon \& G. Palmer (Eds.), Handwriting research and information: An administrator's handbook. (pp. 62-71). Glenview, IL: Scott, Foresman.

Burkhalter, B., \& Wright, J. (1984). Handwriting performance with and without transparent overlays. Journal of Experimental Education, $52,132-135$.

Calkins, L.M. (1986). The art of teaching writing. Portsmouth, NH: Heinemann.

Carlson, K., \& Cunningham, J. (1990). Effect of pencil diameter on the graphomotor skill of preschoolers. Early Childhood Research Quarterly, 5, 279-293.

Christenson, S., Thurlow, M., Ysseldyke, J., \& McVicar, R. (1989). Written language instruction for students with mild handicaps: Is there enough quantity to ensure quality. Learning Disability Quarterly, 12, 219-229.

Coles, R., \& Goodman, Y. (1980). Do we really need those oversized pencils to write with? Theory Into Practice, 19, 194-196.

Coon, G., \& Palmer, G. (Eds.). (1993). Handwriting research and information: An administrator's handbook. Glenview, IL: Scott, Foresman.

Crider, B. (1932). The adaptability of pupils to manuscript writing. Elementary School Journal, 32, 617-622. 
Cutright, P. (1936). Script-print and beginning reading and spelling. Elementary English, 13, 139-141.

Daly, J., \& Shamo, W. (1978). Academic decisions as a function of writing apprehension. Research in the Teaching of English, 12, 55-56.

Duffy, G. (1992). Let's free teachers to be inspired. Phi Delta Kappan, 73, 442-447.

Duvall, B. (1985). Evaluating the difficulty of four handwriting styles used for instruction. ERS Spectrum, 3, 13-20.

Early, G. (1973). The case for cursive writing. Academic Therapy, 9, 105-108.

Edelsky, C. (1990). Whose agenda is this anyway? A response to McKenna, Robinson, and Miller. Educational Researcher, 19, 7-11.

Enstrom, A. (1967). Improving handwriting. Improving College and University Teaching, 15, 168-169.

Faigley, L., Daly, J., \& Witte, S. (1981). The role of writing apprehension in writing performance and competence. Journal of Educational Research, 75, 16-21.

Farris, P. (1982) A comparison of handwriting strategies for primary grade students. Arlington, VA: ERIC Document Reproduction Service (CS 209 360).

Fauke, J., Burnett, J., Powers, M., \& Sulzer-Azeroff, R. (1973). Improvement of handwriting and letter recognition skills: A behavior modification procedure. Journal of Learning Disabilities, 6, 25-29.

Fernald, G. (1943). Remedial techniques in basic school subjects. New York: McGraw-Hill.

Furner, B. (1969a). The perceptual-motor nature of learning in handwriting. Elementary English, 46, 886-894.

Furner, B. (1969b). Recommended instructional procedures in a method emphasizing the perceptual-motor nature of learning in handwriting. Elementary English, 46, 1021-1030.

Furner, B. (1970). An analysis of the effectiveness of a program of instruction emphasizing the perceptual-motor nature of learning in handwriting. Elementary English, 47, 61-69.

Gates, A., \& Brown, H. (1929). Experimental comparisons of print-script and cursive writing. Journal of Educational Research, 20, 1-14.

Gladden, M. (1987). Training second graders in self-evaluation of manuscript letter formation through the use of an electronic card reader. Unpublished doctoral dissertation, The Ohio State University.

Graham, S. (1983). The effects of self-instructional procedures on LD students' handwriting performance. Learning Disability Quarterly, 6, 231-234.

Graham, S. (1986a). A review of handwriting scales and factors that contribute to variability in handwriting scores. Journal of School Psychology, 24, 63-72.

Graham, S. (1986b). The reliability, validity, and utility of three handwriting measurement procedures. Journal of Educational Research, 79, 373-380.

Graham, S. (1990). The role of production factors in learning disabled students' compositions. Journal of Educational Psychology, 82, 781-791.

Graham, S. (1992). Helping students with learning disabilities progress as writers. Interventions, 27, 134-144.

Graham, S., Boyer-Schick, K., \& Tippets, E. (1989). The validity of the handwriting scale from the Test of Written Language. Journal of Educational Research, 82, 166-171.

Graham, S., \& Harris, K.R. (1988). Instructional recommendations for teaching writing to exceptional students. Exceptional Children, 54, 506-512.
Graham, S., \& Harris, K.R. (1989). Cognitive training: Implications for written language. In J. Hughes \& R. Hall (Eds.), Cognitive behavioral psychology in the schools: A comprehensive handbook (pp. 247-279). New York: Guilford Publishing Co.

Graham, S., Harris, K.R., MacArthur, C., \& Schwartz, S. (1991a). Writing instruction. In B. Wong (Ed.), Learning about learning disabilities (pp. 309-343). New York: Academic Press.

Graham, S., Harris, K.R., MacArthur, C., \& Schwartz, S. (1991b). Writing and writing instruction with students with learning disabilities: A review of a program of research. Learning Disability Quarterly, 14, 89-114.

Graham S., Harris, K.R., \& Reid, R. (1992). Developing self-regulated learners. Focus on Exceptional Children, 24, 1-16.

Graham, S., \& Miller, L. (1980). Handwriting research and practice: A unified approach. Focus on Exceptional Children, 13, 1-16.

Graham, S., Schwartz, S., \& MacArthur, C. (in press). Learning disabled and normally achieving students' knowledge of the writing process, attitudes toward writing, and self-efficacy. Journal of Learning Disabilities.

Groff, P. (1964). Who are better writers-The left-handed or the righthanded? Elementary School Journal, 65, 92-96.

Hackney, C. \& Lucas, V. (1993). Zaner-Bloser handwriting: A way to self-expression. Columbus, OH: Zaner-Bloser.

Hallahan, D., Kneedler, R., \& Lloyd, J. (1983). Cognitive behavior modification techniques for learning disabled children: Self-instruction and self-monitoring. In J. McKinney \& L. Feagans (Eds.), Current topics in learning disabilities (Vol. 1, pp. 207-244). New York: Ablex.

Hallahan, D.P., Lloyd, J.W., Kosiewicz, M., Kauffman, J.M., \& Graves, A. (1979). Self-monitoring of attention as a treatment for a learning disabled boy's off-task behavior. Learning Disability Quarterly, 8, 27-36.

Halpin, G., \& Halpin, G. (1976). Special paper for beginning handwriting: An unjustified practice. Journal of Educational Research, 69, 267-269.

Harris. K.R., \& Graham, S. (1992). Helping young writers master the craft: Strategy instruction and self-regulation in the writing process. Boston: Brookline Books.

Hayes, J., \& Flower, L. (1986). Writing research and the writer. American Psychologist, 41, 1106-1113.

Hill, D., Gladden, M., Porter, J., \& Cooper, J. (1982). Variables affecting transition from wide-spaced to normal-spaced paper for manuscript handwriting. Journal of Educational Research, 76, 50-53.

Holbrook, A. (1985). Handwriting instruction. In P. Husen \& N. Postlethwaite (Eds.), International Encyclopedia of Education: Research and Studies. Oxford: Pergammon Press.

Horton, L. (1969). An analysis of illegibilities in the cursive writing of 1,000 selected sixth-grade students. Unpublished doctoral dissertation, The Ohio State University.

Houston, H. (1938). Manuscript writing and progress in reading. Elementary School Journal, 39, 116-118.

Humes, A. (1983). Research on the composing process. Review of Educational Research, 53, 201-216.

Isaacson, S. (1989). Role of secretary vs. author: Resolving the conflict in writing instruction. Learning Disability Quarterly, 12, 209-217.

Johns, J. (1976). The effects of training, self-recording, public charting, and group contingencies on manuscript handwriting legibility. Unpublished doctoral dissertation. The Ohio State University.

Johns, J., Trap, J., \& Cooper, J. (1977). Students' self-recording of manuscript letter strokes. Journal of Applied Behavioral Analysis, $10,509-514$. 
Jordan, D. (no date). Research: Handwriting issues and special needs. Glenview, IL: Scott, Foresman.

Koenke, K. (1986). Handwriting instruction: What do we know? Reading Teacher, 39, 215-216.

Kosiewicz, M. Hallahan, D., \& Lloyd, J. (1981). The effects of an LD student's treatment choice on handwriting performance. Learning Disability Quarterly, 4, 278-286.

Kosiewicz, M., Hallahan, D., Lloyd, J., \& Graves, A. (1982). Effects of self-instruction and self-correction procedures on handwriting performance. Learning Disability Quarterly, 5, 71-81.

Lally, M. (1982). Computer-assisted handwriting instruction and visual/kinesthetic feedback processes. Applied Research in Mental Retardation, 3, 397-405.

Lamme, L., \& Ayris, B. (1983). Is the handwriting of beginning writers influenced by writing tools? Journal of Research and Development in Education, 17, 32-38.

Leung, E., Treblas, P., Hill, D., \& Cooper, J. (1979). Space size and accuracy of first-grade students' manuscript writing. Journal of Educational Research, 73, 79-81.

Lewis, E. (1964). An analysis of children's manuscript writing. Unpublished doctoral dissertation. University of California, Berkeley.

Long, H., \& Mayer, W. (1931). Printing versus cursive writing in beginning reading instruction. Journal of Educational Research, 24, 350-355.

MacArthur, C., \& Graham, S. (1987). Learning disabled students' composing with three methods: Handwriting, dictation, and word processing. Journal of Special Education, 21, 22-42.

MacArthur, C., Schwartz, S., \& Graham, S. (1991). A model for writing instruction: Integrating word processing and strategy instruction into a process approach to writing. Learning Disabilities Research and Practice, 6, 230-236.

Markham, L. (1976). Influence of handwriting quality on teacher evaluation of written work. American Educational Research Journal, 13, 277-283.

McDougal, Littell. (1993). Handwriting connections. Evanston, IL: McDougal, Littell Co.

McGinnis, H., Kleffner, R., \& Goldstein, R. (1963). Teaching aphasic children. Washington, D.C.: The Volta Bureau.

McLaughlin, T. (1983). Effects of self-recording for on-task and academic responding: A long-term analysis. Journal of Special Education Technology, 6, 5-12.

Oglesby, B. (1982). A comparative study of the difference in the manuscript handwriting performance of six below-average secondgrade students who experienced the D'Nealian method of handwriting instruction for a nine-week period when compared to six belowaverage second-grade students who experienced the Zaner-Bloser method of handwriting instruction for a nine-week period, as measured by four judges' scores on a teacher-made check-list. Unpublished master's thesis. University of North Florida, Jacksonville.

O'Leary, S., \& Dubey, D. (1979). Applications of self-control procedures by children: A review: Journal of Applied Behavior Analysis, 12, 449-465.

Ourada, E. (1993). Legibility of third-grade handwriting: D'Nealian handwriting versus traditional Zaner-Bloser. In G. Coon \& G. Palmer (Eds.), Handwriting research and information: An administrator's handbook (pp. 72-87). Glenview, IL: Scott, Foresman.
Parker, T. (1972). The developmental nature of children's ability to use varying diameter writing instruments. Unpublished doctoral dissertation. University of Virginia.

Robin, A.L., Armel, S., \& O'Leary, D.K. (1975). The effects of selfinstruction on writing deficiencies. Behavior Therapy, 6, 178-187.

Scardamalia, M., \& Bereiter, C. (1986). Written composition. In M. Wittrock (Ed.), Handbook of research on teaching. (3rd ed., pp. 778-803). New York: Macmillan.

Scardamalia, M., Bereiter, C., \& Goelman, H. (1982). The role of production factors in writing ability. In M. Nystrand (Ed.), What writers know: The language, process and structure of written discourse (pp. 173-210). New York: Academic Press.

Stowitschek, J. (1978). Applying programming principles to remedial handwriting practice. Journal of Special Education Technology, 1, 21-26.

Stowitschek, J., Ghezzi, P., \& Safely, K. (1987). "I'd rather do it myself:" Self-evaluation and correction of handwriting. Education and treatment of children, 10, 209-224.

Taylor, B., Harris, L., \& Pearson, P. (1988). Reading difficulties: Instruction and assessment. New York: Random House.

Templin, E. (1963). The legibility of adult manuscript, cursive, or manuscript-cursive handwriting styles. In V. Herrick (Ed.), New horizons for handwriting research. Madison, WI: University of Wisconsin Press.

Thurber, D. (1983). D'Nealian manuscript-An aid to reading development. Arlington, VA: ERIC Document Reproduction Service (CS 007 057).

Thurber, D. (1993a). How D'Nealian handwriting meets the needs of all writers. In G. Coon \& G. Palmer (Eds.), Handwriting research and information; An administrator's handbook (pp. 50-61). Glenview, IL: Scott, Foresman.

Thurber, D. (1993b). D'Nealian Handwriting. Glenview, IL: Scott, Foresman.

Trap-Porter, J., Cooper, J., Hill, D., Swisher, K., \& LaNunziata, L. (1984). D'Nealian and Zaner-Bloser manuscript alphabets and initial transition to cursive handwriting. Journal of Educational Research, 77, 343-345.

Trap-Porter, J., Gladden, M., Hill, D., \& Cooper, J. (1983). Space size and accuracy of second and third grade students' cursive handwriting. Journal of Educational Research, 76, 231-233.

Voorhis, T. (1931). The relative merits of cursive and manuscript writing. New York: Teacher's College.

Waggoner, J., LaNunziata, L., Hill, \& Cooper, J. (1981). Space size and accuracy of kindergarten and first grade students' manuscript handwriting. Journal of Educational Research, 74, 182-184.

Watson, D. (1989). Defining and describing whole language. Elementary School Journal, 90, 129-141.

White, J., Cunningham, S., \& Brewer, N. (1989). Computer-assisted instruction in letter formation skills. Journal of Computer-Based Research, 16, 122-125.

Wiles, M. (1943). The effects of different sizes of tools on the handwriting of beginners. Elementary School Journal, 43, 412-414.

Zettersten, A. (1969). A statistical study of the graphic system of presentday American English. Lund, Sweden: Studentlitteratur. 


\section{Counseling the Gifted and Talented}

Edited by Linda Kreger Silverman

\section{The Most Comprehensive Guide for Counseling Gifted Individuals}

In this new book the authors examine both the cognitive complexity and emotional intensity of gifted children and discuss the need for modification of counseling techniques. They present a developmental model to enable counselors to orchestrate a program of prevention rather then remediation. Specific strategies for individual and group counseling are provided to assist counselors, psychologists, and teacher-counselors in meeting the unique social and emotional needs of these individuals.

\section{PART I. UNDERSTANDING GIFTEDNESS}

1. The Gifted Individual by Linda Silverman

2. The Quest for Meaning: Counseling Issues with Gifted Children and Adolescents by Deirdre Lovecky

3. A Developmental Model for Counseling the Gifted by Linda Silverman

PART II. THE COUNSELING PROCESS

4. Techniques for Preventive Counseling by Linda Silverman

5. Group Counseling with Gifted Students by Nick Colangelo \& Jean Sunde Peterson

6. Counseling Gifted Learning Disabled Students: Individual and Group Counseling Techniques by Sal Mendaglio

7. Counseling Families by Linda Silverman
The authors discuss specific aspects of counseling gifted students, such as teaching them how to establish positive relationships with peers, cope with their perfectionism, develop ethical leadership skills, and make appropriate career choices. There are chapters on individual and group techniques, counseling gifted/learning disabled students, students at risk, counseling families, assessment tools, academic advisement, career counseling, roles of school personnel, multicultural counseling, and gender issues.

PART III. COUNSELING IN THE SCHOOLS

8. The Roles of Educational Personnel in Counseling the Gifted by Joyce VanTasselBaska \& Leland Baska

9. Academic Counseling for the Gifted by Joyce VanTassel-Baska

10. Career Counseling by Linda Silverman

11. Assessment Tools for Counselors by John Feldhusen

\section{PART IV. SPECIAL ISSUES}

12. Gifted Students at Risk by Ken Seeley

13. Multicultural Counseling by Kathy Evans

14. Social Development, Leadership, and Gender Issues by Linda Silverman

\section{CONCLUSION}

\section{APPENDICES}

Bibliography for Parents

Books for Children Featuring Gifted Children

Biographies for Gifted Students

Periodicals in Gifted Education

Resources for Counseling and Assessment 


\section{Professional update}

\section{October 15-17, 1992}

Council for Learning Disabilities

Allis Plaza Hotel

Kansas City, Missouri

Contact: CLD

P.O. Box 40303

Overland Park, KS 66204

\section{November 4-8, 1992}

National Association for Gifted Children

Westin Bonaventure Hotel

Los Angeles, California

Contact: NAGC

Suite 1002

1155 15th Street, NW

Washington, DC 20005

\section{November 12-14, 1992}

CEC - Culturally and Linguistically Diverse

Exceptional Children Conference

Marriott City Center Hotel

Minneapolis, Minnesota

Contact: CEC

1920 Association Drive

Reston, VA 22091

\section{November 19-21, 1992}

Association for Persons with Severe Handicaps

Marriott Hotel

San Francisco, California

Contact: TASH

11201 Greenwood Ave. North

Seattle, WA 98133

\section{November 20-23, 1992}

American Speech-Language-Hearing Association San Antonio, Texas

Contact: ASHA

10801 Rockville Pike

Rockville, MD 20852

\section{December 3-5, 1992}

CEC - Early Childhood Conference on

Children with Special Needs

Washington Hilton Hotel

Washington, DC

Contact: CEC

1920 Association Drive

Reston, VA 22091

\section{PERMISSIONS AND COPYRIGHT}

All rights are reserved. No part of this publication may be reproduced, photocopied, faxed, stored in a retrieval system, or transmitted, in any form or by any means, electronic, mechanical, recording or otherwise, without the prior written permission of the publisher.
Back issues are available for sale. Reproduction requires permission and payment of fees. It is illegal and a violation of Federal copyright law to reproduce this publication without permission. Direct all inquiries to the permissions editor. 